\title{
Analisis Faktor Risiko Lelang Di Bawah Perkiraan Kinerja Kualitas Proyek Konstruksi Bangunan di Kota Trenggalek Jawa Timur
}

\author{
Rekso Ajiono ${ }^{1}$, Heri Wahyudiono ${ }^{2}$ \\ ${ }^{1,2}$ Fakultas Teknik Universitas Kadiri
}

email : rekso_ajiono@unik-kediri.ac.id,heri_wahyudiono@unik-kediri.ac.id

\begin{abstract}
A plan will correct delays in planning and control is not done properly. Various things can occur in a construction project that can lead to increased processing time so that the project becomes hampered. The purpose of the research is to discuss and classify the factors that cause delays in the implementation of development projects in the Trenggalek Regency and to accept factors of delay related to the use of costs. This data processing uses the SPSS (Statistical Product and Service Solution) computer program version 17.00. The data analysis technique uses validity, reliability, factor analysis, classical assumption and multiple linear regression. The results of the study are 3 new factors obtained from the extraction of factor analysis are: Changes in scope and employment documents (Xb1), Coordination and transportation of resources and expertise of manpower (Xb2), Evaluation and planning systems (Xb3) and produce one model of equation multiple linear to explain the relationship of the three factors above with costs.
\end{abstract}

Keywords: Engineer, SPSS, Heteroscedasticity and Normality.

\begin{abstract}
ABSTRAK
Sebuah rencana akan memperbaiki keterlambatan dalam perencanaan dan kontrol tidak dilakukan dengan benar. Berbagai hal dapat terjadi dalam proyek konstruksi yang dapat menyebabkan peningkatan waktu pemrosesan sehingga proyek menjadi terhambat. Tujuan dari penelitian ini adalah untuk membahas dan mengklasifikasikan faktor-faktor yang menyebabkan keterlambatan dalam pelaksanaan proyek-proyek pembangunan di Kabupaten Trenggalek dan untuk menerima faktor keterlambatan terkait dengan penggunaan biaya. Pemrosesan data ini menggunakan program komputer SPSS (Produk Statistik dan Solusi Layanan) versi 17.00. Teknik analisis data menggunakan validitas, reliabilitas, analisis faktor, asumsi klasik, dan regresi linier berganda. Hasil penelitian ini adalah 3 faktor baru yang diperoleh dari ekstraksi analisis faktor yaitu: Perubahan ruang lingkup dan dokumen pekerjaan (Xb1), Koordinasi dan transportasi sumber daya dan keahlian tenaga kerja (Xb2), Evaluasi dan sistem perencanaan (Xb3) dan menghasilkan satu model persamaan linear berganda untuk menjelaskan hubungan ketiga faktor di atas dengan biaya.
\end{abstract}

Kata Kunci: Insinyur, SPSS, Heteroskedastisitas dan Normalitas

\section{PENDAHULUAN}

Proyek sering mengalami keterlambatan. Jeleknya, keterlambatan proyek sering berulang pada aspek yang dipengaruhi maupun pada aspek yang mempengaruhi karena pelaku proyek sering menganggap remeh keterlambatan proyek dan tidak menjadikan kejadian ini sebagai pelajaran dan pengalaman penting dalam pelaksanaan proyek berikutnya. Keterlambatan proyek akan berdampak pada aspek lain dalam proyek. Sebagai contoh, meningkatnya biaya untuk usaha mempercepat pekerjaan dan bertambahnya biaya overhead proyek. Dampak lain yang 
juga sering terjadi adalah penurunan kualitas karena pekerjaan terpaksa dilakukan lebih cepat dari yang seharusnya sehingga memungkinkan beberapa hal teknis dilanggar demi mengurangi keterlambatan proyek. Keterlambatan pelaksanaan proyek memberikan pengaruh yang cukup berarti terhadap biaya. Tambahan biaya yang harus disediakan oleh Penyedia Jasa baik berupa biaya langsung dan biaya tidak langsung merupakan suatu keharusan untuk mengejar keterlambatan pelaksanaan proyek demi nama baik sebuah perusahaan. Tidak jarang ditemukan suatu proyek yang terkadang biaya tidak langsungnya lebih besar dari biaya langsung. Biaya tidak langsung ini merupakan biaya overhead, baik yang berkaitan dengan proyek atau kantor pusat.

\section{METODE PENELITIAN}

\subsection{Dasar Teori}

Keterlambatan Proyek Keterlambatan proyek kontruksi berarti bertambahnya waktu pelaksanaan proyek yang telah direncanakan dan tercantum dalam dokumen kontrak. Penyelesaian pekerjaan tidak tepat waktu adalah merupakan kekurangan dari tingkat produktifitas dan sudah barang tentu kesemuanya ini akan mengakibatkan pemborosan dalam pembiayaan, baik pembiayaan langsung maupun tidak langsung. Peran aktif manajemen merupakan salah satu kunci utama keberhasilan pengelolaan proyek. Pengkajian jadwal proyek diperlukan untuk menentukan langkah perubahan mendasar agar keterlambatan penyelesaian proyek dapat dihindari atau dikurangi. Dari kedua jenis struktur biaya konstruksi, terdapat perbedaan yang mencolok. Pada struktur estimasi biaya yang dimiliki oleh AACE memperlihatkan lebih detail jika dibandingkan dengan PAHS. Terlihat pada komponen - komponen biaya tidak langsung, yaitu adanya pemisahan antara komponen overhead dan kondisi umum (general condition). Sedangkan pada PAHS biaya umum masuk ke dalam overhead.

\subsection{Biaya Langsung}

Proyek Konstruksi Biaya langsung adalah semua biaya yang menjadi komponen permanen hasil akhir proyek, terdiri dari biaya material, biaya peralatan, biaya upah tenaga kerja dan biaya subkontraktor (Oberlender dan Peurifoy, 2002).

\subsection{Biaya Tidak Langsung Proyek Konstruksi}

Biaya tidak langsung proyek konstruksi adalah biaya yang tidak berkaitan secara langsung dalam pelaksanaan proyek konstruksi. Biaya tidak langsung dialokasikan untuk pekerjaan yang berdasarkan pada beberapa komponen biaya langsung seperti waktu penyelesaian pekerjaan, biaya material atau keduanya (AACE, 1992).

\subsection{Analisis Regresi Linier Berganda}


Analisis ini digunakan untuk mengetahui pengaruh variabel independen yaitu faktor - faktor penyebab keterlambatan penyelesaian proyek konstruksi $(\mathrm{X})$ terhadap variabel dependen yaitu faktor penggunaan biaya akibat keterlambatan tersebut (Y) dengan rumus :

$\mathrm{Y}_{\mathrm{i}}=\mathrm{b}_{1}+\mathrm{b}_{2} \mathrm{X}_{2 \mathrm{i}}+\mathrm{b}_{3} \mathrm{X}_{3 \mathrm{i}}+\ldots+\mathrm{b}_{\mathrm{ki}} \mathrm{X}_{\mathrm{ki}}+\mathrm{e}_{\mathrm{i}}$

$\mathrm{Y}=$ Faktor penggunaan biaya akibat keterlambatan

$\mathrm{X}_{1}, \mathrm{X}_{2}, \mathrm{X}_{3}, \ldots ., \mathrm{X}_{\mathrm{k}}=$ Faktor - faktor penyebab keterlambatan

$\mathrm{b} 0=$ Konstanta

$b_{1}, b_{2}, b_{3}, \ldots, b_{k}=\quad$ Koefisien regresi variabel $X_{1}, X_{2}, X_{3}, \ldots ., X_{k}$

$\mathrm{e}$ (epsilon) $\quad=\quad$ Kesalahan pengganggu (disturbence's error)

Statistik Uji Validitas

Menurut Azwar, 1994 : 118 (dalam Agus Winarno, 2011), validitas adalah seberapa cermat suatu kuesioner melakukan fungsi ukurnya. Sebuah kuesioner bisa dikatakan valid jika kuesioner tersebut benar - benar mengukur apa yang harus diukur. Pengukuran validitas ini dilakukan dengan menghitung korelasi antara total jawaban responden terhadap setiap pertanyaan. Pengolahan data dengan menggunakan bantuan program SPSS (Statistical Product and Service Solution) versi 17.00 Tinggi rendahnya validitas suatu angket dihitung dengan teknik korelasi, dengan rumus :

$$
r_{x y}=\frac{\mathrm{N} \sum \mathrm{XY}-\left(\sum \mathrm{X}\right)\left(\sum \mathrm{Y}\right)}{\sqrt{\left(\mathrm{N} \sum \mathrm{X}^{2}-\left(\sum \mathrm{X}\right)^{2}\right)\left(\mathrm{N} \sum \mathrm{Y}^{2}-\left(\sum \mathrm{Y}\right)^{2}\right)}}
$$

Kriteria uji validitas secara singkat adalah (rule of tumb) adalah 0,3 . Jika korelasi sudah lebih besar dari 0,3 maka kuesioner atau pertanyaan yang dibuat dikategorikan sahih / valid. (Bambang Setiaji, $2008: 25$ )

\subsection{Uji Reliabilitas}

Yang dimaksud dengan realibilitas adalah derajat ketepatan, ketelitian atau keakuratan yang ditunjukkan oleh instrument pengukuran. Selain itu, juga untuk memastikan bahwa responden cukup konsisten dalam memberikan jawaban (reliabilitas). Analisis keandalan butir bertujuan untuk menguji konsistensi butir - butir pertanyaan dalam mengungkap indicator. Reliabilitas test dapat diestimasikan dengan menggunakan analisis Alpha Cronbach, dengan rumus (Husein, $2003: 96$ )

$$
r_{i}=\left(\frac{k}{k-1}\right)\left(1-\frac{\sum \sigma_{b}^{2}}{\sigma_{t}^{2}}\right)
$$

Menurut Santoso dan Ashari (2005 : 251) bahwa penelitian responden dianggap reliabel jika mencapai alpha lebih besar dari 0,6 . Pengolahan data dengan menggunakan bantuan program 
SPSS versi 19.00

\subsection{Analisis Ekonometrik (Pengujian Model) pada regresi Linier Berganda}

Setelah model kita peroleh, maka kita harus menguji model tersebut sudah termasuk BLUE (Best Linier Unbiased Estimator) atau tidak. Suatu model dikatakan BLUE bila memenuhi persyaratan sebagai berikut :

Linieritas

Untuk menguji linieritas hubungan 2 variabel maka kita harus membuat diagram pancar (scatter plot) antara 2 variabel tersebut. Dari sini bisa terlihat apakah titik - titik data membentuk pola linier atau tidak.

Heterokedastisitas

Salah satu asumsi dalam regresi berganda adalah uji heterkedastisitas. Asumsi heterokedastitas adalah asumsi dalam regresi dimana varians dari residual tidak sama untuk pengamatan ke pengamatan yang lain. Dalam regresi, salah satu asumsi yang harus dipenuhi adalah bahwa varians dari residual dari satu pengamatan ke pengamatan yang lain tidak memiliki pola tertentu.

Autokorelasi

Uji autokorelasi merupakan pengujian asumsi dalam regresi dimana variabel dependen tidak berkorelasi dengan dirinya sendiri. Untuk mendeteksi gejala autokorelasi kita menggunakan uji Durbin - Watson (DW). Uji ini menghasilkan nilai DW hitung (d) dan nilai DW table (dL $\& \mathrm{du})$. Aturan pengujiannya adalah :

$$
\begin{array}{lll}
\mathrm{d}<\mathrm{d}_{\mathrm{L}} & = & \text { terjadi masalah autokorelasi yang positif yang } \\
& & \begin{array}{l}
\text { perlu perbaikan } \\
\text { ada masalah autokorelasi positif tetapi lemah, }
\end{array} \\
\mathrm{d}_{\mathrm{L}}<\mathrm{d}<\mathrm{d}_{\mathrm{u}} & & \begin{array}{l}
\text { dimana perbaikan akan lebih baik } \\
\text { tidak ada masalah autokorelasi }
\end{array} \\
\mathrm{d}_{\mathrm{u}}<\mathrm{d}<4-\mathrm{d}_{\mathrm{u}} & = & \text { Masalah autokorelasi lemah, dimana dengan } \\
4-\mathrm{d}_{\mathrm{u}}<\mathrm{d}, 4-\mathrm{d}_{\mathrm{L}} & = & \text { perbaikan akan lebih baik } \\
& \text { masalah autokorelasi serius }
\end{array}
$$

SPSS ( Statistical Product and Service Solution )

Pada dasarnya computer berfungsi mengolah data menjadi informasi yang berguna bagi pengguna computer. Data yang diolah dimasukkan sebagai input, kemudian dengan proses pengolahan data oleh computer dihasilkan output berupa informasi untuk kegunaan lebih lanjut. Berikut ini sedikit gambaran terntang cara kerja computer dengan program SPSS (Statistical Product and Service Solution) dalam mengolah data.

Tabel 1: Sepuluh Faktor Penyebab Keterlambatan 


\begin{tabular}{|c|c|c|}
\hline No & Variabel & Peneliti \\
\hline 1 & $\begin{array}{l}\text { Perubahan desain / detail pekeriaan pada wakty } \\
\text { pelaksanaan }\end{array}$ & $\begin{array}{l}\text { Budiman Prabovo: } \\
\text { I.A. Rai Widhiawati } \\
\text { Suyatno }\end{array}$ \\
\hline 2 & Adanva banvak (sering) pekeria antambah & Budiman Prabovo \\
\hline 3 & $\begin{array}{l}\text { Proses perminta an dan persetujuan contoh } \\
\text { bahan yang lama }\end{array}$ & $\begin{array}{l}\text { BudimanPraboyo \& } \\
\text { I.A. Rai Widhiawati }\end{array}$ \\
\hline 4 & $\begin{array}{l}\text { Perubahan lingkup pekeriaan pada waktu } \\
\text { pelaksanaan }\end{array}$ & $\begin{array}{l}\text { Budiman Prabovo \& } \\
\text { Suvatno }\end{array}$ \\
\hline 5 & Kurangnyakeahlian tenaga kerja & $\begin{array}{l}\text { Budiman Praboyo \& } \\
\text { I.A. Rai Widhiawati }\end{array}$ \\
\hline 6 & Keterlambatanpembayaranoleh pemilik & $\begin{array}{l}\text { Budiman Praboyo; } \\
\text { I.A. Rai Widhiawati } \\
\text { Suyatmo }\end{array}$ \\
\hline 7 & $\begin{array}{l}\text { Mobilisasi sumber daya (bahan, alat, tenaga } \\
\text { kerja)yang lambat }\end{array}$ & $\begin{array}{l}\text { Budiman Praboyo \& } \\
\text { I.A. Rai Widhiawati }\end{array}$ \\
\hline 8 & $\begin{array}{l}\text { Jumlah pekerja y ang kurang memadai / sesuai } \\
\text { dengan aktifitas yang a da }\end{array}$ & $\begin{array}{l}\text { Suyatno \& Budiman } \\
\text { Praboyo }\end{array}$ \\
\hline 9 & $\begin{array}{l}\text { Tidak lengkaprrya identifikasi jenis pekerjaan } \\
\text { yang harus ada }\end{array}$ & $\begin{array}{l}\text { I.A. Rai Widhia wati } \\
\text { \& Budiman Prabovo }\end{array}$ \\
\hline 10 & Akses ke lokasi proyek sulit & $\begin{array}{l}\text { Suyatno; Budiman } \\
\text { Praboyo; I.A. Rai } \\
\text { Widhiawati }\end{array}$ \\
\hline
\end{tabular}

Sumber : Rangkuman Hasil Penelitian Sebelumnya

\subsection{Bagan Alur Penelitian}

Penelitian ini termasuk jenis penelitian survey yaitu penelitian yang mengambil sampel dari suatu populasi dan menggunakan kuesioner sebagai alat pengumpulan data menurut Singaribun, 1995 (salam Suyatno, 2010). Ada tiga persyaratan penting dalam mengadakan kegiatan penelitian yaitu :

Sistematis, apabila penelitian dilaksanakan menurut pola tertentu, dari yang paling sederhana sampai kompleks hingga tercapai tujuan secara efektif dan efisien.

Berencana, apabila penelitian denganadanya unsur kesengajaan dan sebelumnya sudah dipikirkan langkah - langkah pelaksanaannya.

Mengikuti konsep ilmiah, apabila mulai dari awal sampai akhir kegiatan penelitian mengikuti cara- cara yang sudah ditentukan, yaitu prinsip memperoleh ilmu pengetahuan. Perancangan Kuesioner

Kuesioner dirancang dalam tiga kelompok. Data responden, pada bagian ini dikumpulkan data mengenai Jabatan responden, pengalaman responden, Jenis proyek konstruksi di wilayah Trenggalek yang telah dikerjakan / ditangani.

Data proyek

Pada bagian ini akan didapat data mengenai jenis proyek konstruksi dan nilai proyek yang pernah dikerjakan oleh responden, kemudian pengaruh terhadap biaya yang telah direncanakan.

Data persepsi responden terhadap penyebab keterlambatan proyek. Bagian ini bertujuan untuk mengetahui sejauh mana faktor keterlambatan proyek tersebut berpengaruh pada keterlambatan pelaksanaan proyek konstruksi di wilayah Trenggalek.

Metode Analisis Data 
Tujuan analisis data menyederhanakan data ke dalam bentuk yang lebih mudah dibaca dan diinterpretasi. Dalam proses ini sering kali digunakan statistic karena memang salah satu fungsi statistik adalah menyederhanakan data. Pengukuran kuesioner dilakukan dengan skala linkert dimana responden diberi pilihan (option) yang kemudian tinggal memilih derajat kesetujuan / ketidaksetujuannya atas pertanyaan yang diajukan.

\section{ANALISIS DATA DAN PEMBAHASAN}

\subsection{Tinjauan Umum}

Faktor tersebut adalah perubahan desain / detail pekerjaan pada waktu pelaksanaan (X1), adanya banyak (sering) pekerjaan tambah (X2), proses permintaan dan persetujuan contoh bahan yang lama (X3), perubahan lingkup pekerjaan pada waktu pelaksanaan (X4), kurangnya keahlian tenaga kerja (X5), keterlambatan pembayaran oleh pemilik (X6), mobilisasi sumber daya (bahan, alat, tenaga kerja) yang lambat (X7), jumlah pekerja yang kurang memadai / sesuai dengan aktifitas pekerjaan yang ada (X8), tidak lengkapnya identifikasi jenis pekerjaan yang harus ada (X9), akses ke lokasi proyek sulit (X10). Sesuai dengan tahapan penelitian yang telah diutarakan pada bab sebelumnya setelah didapatkan data primer yang dibutuhkan, kemudian dilanjutkan dengan analisis data dan pembahasan untuk mendapatkan jawaban dari rumusan yang ada. Analisis data ini dikerjakan dengan bantuan program SPSS (Statistical Product and Service Solution) versi 17.00 .

Tabel 2: Faktor Penyebab Keterlambatan Penyelesaian Proyek Konstruksi di Wilayah Kabupaten Trenggalek

\begin{tabular}{|l|l|l|}
\hline No & Variabel & Kode \\
\hline 1 & Perubahan desain / detail pekerjaan pada waktu pelaksanaan & $\mathrm{X} 1$ \\
\hline 2 & Adanya banyak (sering) pekerjaan tambah & $\mathrm{X} 2$ \\
\hline 3 & Proses permintaan dan persetujuan contoh bahan yang lama & $\mathrm{X} 3$ \\
\hline 4 & Perubahan lingkup pekerjaan pada waktu pelaksanaan & $\mathrm{X} 4$ \\
\hline 5 & Kurangnya keahlian tenaga kerja & $\mathrm{X} 5$ \\
\hline 6 & Keterlambatan pembayaran oleh pemilik & $\mathrm{X} 6$ \\
\hline 7 & Mobilisasi sumber daya (bahan, alat, tenaga kerja) yang lambat & $\mathrm{X} 7$ \\
\hline 8 & $\begin{array}{l}\text { Jumlah pekerja yang kurang memadai / sesuai dengan aktifitas } \\
\text { yang ada }\end{array}$ & $\mathrm{X} 8$ \\
\hline 9 & Tidak lengkapnya identifikasi jenis pekerjaan yang harus ada & $\mathrm{X} 9$ \\
\hline 10 & Akses ke lokasi proyek sulit & $\mathrm{X} 10$ \\
\hline 11 & $\begin{array}{l}\text { Faktor - faktor tersebut di atas bagaimana pengaruhnya } \\
\text { terhadap biaya }\end{array}$ & $\mathrm{X} 11$ \\
\hline
\end{tabular}

Sumber: Hasil Olahan Data Program SPSS

\subsection{Uji Validitas dan Reliabilitas}

Uji Validitas 
Untuk mengetahui kevalidtannya, dari ke - 10 faktor dalam bentuk kuesioner yang disampaikan kepada responden dilakukan uji validitas terhadap setiap factor dalam kelompok variable dengan menggunakan program SPSS Versi 17.00. Hasil tes validitas dapat dilihat pada kolom Correlated Item Total Correlation (lihat tabel). Criteria uji validitas secara singkat (rule of tumb) adalah 0,3. jika korelasi sudah lebih besar dari 0,3 maka kuesioner / pertanyaan yang dibuat dikatakan sahih valid.

Tabel 3: Uji Validitas

\begin{tabular}{|l|l|l|l|}
\hline & $\begin{array}{l}\text { ScaleMean if Item } \\
\text { Deleted }\end{array}$ & $\begin{array}{l}\text { Scale Variance if } \\
\text { Item Deleted }\end{array}$ & $\begin{array}{l}\text { Corrected Item } \\
\text { - Total Correlation }\end{array}$ \\
\hline X1 & 17.63 & 20.087 & .440 \\
\hline X2 & 17.70 & 19.446 & .474 \\
\hline X3 & 17.70 & 17.292 & .690 \\
\hline X4 & 17.85 & 20.131 & .509 \\
\hline X5 & 1.72 & 20.512 & .375 \\
\hline X6 & 17.78 & 19.717 & .405 \\
\hline X7 & 17.53 & 18.922 & .577 \\
\hline X8 & 17.55 & 19.946 & .361 \\
\hline X9 & 17.72 & 19.589 & .399 \\
\hline X10 & 17.68 & 19.251 & .546 \\
\hline S4
\end{tabular}

Sumber : Hasil Olahan Data Program SPSS

Uji Reliabilitas

Uji reliabilitas digunakan dengan tujuan untuk mengetahui siifat dari alat ukur yang digunakan, dalam arti apakah alat ukur tersebut akurat, stabil, dan konsisten. Instrument yang digunakan dalam penelitian ini dikatakan andal (reliable) apabila memiliki cronbach's alpha lebih dari 0,6. Hasil tes reliabilitas dapat dilihat pada kolom Cronbach's Alpha If Item Deleted (lihat tabel).

\subsection{Analisis Faktor (Factor Analysis)}

Analisis faktor merupakan suatu kelas prosedur yang dipergunakan untuk merduksi dan meringkas data. Agar analisis faktor bisa tepat dipergunakan variabel - variabel yang akan dianalisis harus berkorelasi. Apabila koefisien korelasi antar - variabel terlalu kecil, 
hubungan lemah, analisis faktor tidak tepat. Banyaknya faktor lebih sedikit daripada banyaknya variabel. Faktor - faktor diekstraksi (extracted) sedemikian rupa sehingga factor yang pertama menyumbang (memberikan andil) terbesar terhadap seluruh varian dari seluruh variabel asli, faktor kedua menyumbar terbesar yang kedua, faktor ketiga menyumbang terbesar ketigam dan begitu seterusnya sehingga proses pencarian faktor yang sudah berhasil diekstraksi sudah mencapai $60 \%$ atau lebih.

\subsection{Uji KMO dan Bartlett's Test}

Uji statistic KMO (Kaiser - Mayer - Olkin) digunakan untuk mengukur kecukupan sampling (sampling adequacy). Indeks ini membandingkan besarnya koefisien korelasi terobeservasi dengan koefisien korelasi parsial. Nilai KMO yang kecil menunjukan bahwa korelasi antar pasangan variabel tidak bisa diterangkan oleh variabel lainnya dan analisis faktor mungkin tidak tepat. Analisis faktor akan menjadi tepat apabila nilai KMO yang diperoleh $>0.50$. untuk menguji ketepatan model faktor tersedia statistik formal yaitu bartlett's test of sphericity bahwa variabel tak berkorelasi di dalam populasi.

\subsection{Ekstraksi Faktor (Factor Extructed)}

Dalam teknik analisis faktor terdapat banyak metode yang dapat digunakan untuk mengekstraksi atau mereduksi faktor. Pada penelitian ini peneliti memakai metode principal component analysis dengan menggunakan program SPSS v.17.

\subsection{Rotasi Faktor}

Rotasi faktor digunakan untuk mengubah (mentranformasi) matrix factor menjadi matrix yang lebih sederhana yang lebih mudah untuk diinterpretasi (disimpulkan). Metode rotasi yang paling banyak dipergunakan dalam teknik analisis faktor ialah varimax procedure, yang menghasilkan faktor yang tidak berkorelasi, bebas dari multicollineriy.

\subsection{Uji Asumsi Klasik / Analisis Ekonometrik}

Dalam regresi linier berganda terdapat beberapa asumsi yang harus dipenuhi sehingga persamaan regresi yang dihasilkan akan valid jika digunakan untuk memprediksi. Penggunaan asumsi ini merupakan konsekuensi dalam menghitung persamaan regresi linier. Beberapa asumsi tersebut meliputi asumsi data yang terdistribusi secara normal, asumsi multikolinieritas, asumsi autokoreksi, asumsi heterokedastisitas dan asumsi liniritas. Dalam buku - buku statistic asumsi ini disebut analisis ekonometrik.

\subsection{Regresi Linier Berganda}

Regresi linier berganda digunakan untuk mengetahui pengaruh dari variabel bebas perubahan lingkup dan dokumen pekerjaan, koordinasi dan transportasi sumber daya serta keahlian tenaga kerja, sistem evaluasi dan perencanaan terhadap variabel terikat pemakaian biaya. Program SPSS menyediakan beberapa metode untuk mengetahui besarnya tingkat pengaruh dari 
variabel bebas tersebut, antara lain metode enter, metode stepwise, metode backward, metode forward, dan metode remove.

\subsection{Koefisien Determinasi Berganda}

Koefisien determinasi berganda yang diperoleh dari uji linier berganda yaitu sebesar R2 = 0,716. Hal ini berarti bahwa $71,6 \%$ pemakaian biaya dijelaskan oleh variabel bebas yaitu perubahan lingkup dan dokumen pekerjaan, koordinasi dan transportasi sumber daya serta keahlian tenaga kerja, system evaluasi dan perencanaan. Sedangkan selebihnya dijelaskan oleh variabel lain yang belum disebutkan pada penelitian ini. Predictors : (constant), perubahan lingkup dan dokumen pekerjaan, koordinasi dan transportasi sumber daya serta keahlian tenaga kerja, system evaluasi dan perencanaan. Dependent Variable : Biaya

\section{KESIMPULAN DAN SARAN}

\subsection{Kesimpulan}

Berdasarkan analisis data dan pembahasannya yang telah dilakukan dalam penelitian ini dapat ditarik kesimpulan sebagai berikut :

Dari teknik analisis faktor dihasilkan 3 (tiga) faktor baru penyebab keterlambatan penyelesaian proyek di wilayah Kabupaten Trenggalek yang merupakan hasil ekstraksi dari sepuluh faktor asli. Penentuan variabel baru tersebut berdasarkan eigenvalues dan persentase komulatif, hanya variabel dengan eigenvalues lebih dari $60 \%$. Tiga faktor tersebut sebagai berikut :

Perubahan lingkup dan dokumen pekerjaan (Xb1)

Koordinasi dan transportasi sumber daya serta keahlian tenaga kerja (Xb2)

Sistem evaluasi dan perencanaan (Xb3).

Dari uji regresi linier berganda diperoleh satu persamaan yaitu $\mathrm{Y}=3,809+0,079 \mathrm{Xb} 1+0,172$ $\mathrm{Xb} 2+0,013 \mathrm{Xb} 3$. Dari

Adapun saran yang dapat dijadikan bahan pertimbangan yaitu :

Sebagai bahan pertimbangan bagi perusahan yang bergerak di bidang konstruksi untuk dapat menghindari keterlambatan penyelesaian proyek konstruksi Sebagai masukan untuk pemerintah Kabupaten Trenggalek dalam mengawasi proyek konstruksi agar tidak terjadi keterlambatan penyelesaian proyek.

Dalam penelitian berikutnya diharapkan melakukan survey kembali setelah diperoleh faktor yang baru untuk memperoleh data yang lebih akurat.

\subsection{Saran}

persamaan tersebut dapat dikatakan bahwa ketiga variabel bebas mempunyai pengaruh positif terhadap pemakaian biaya artinya meningkatnya salah satu dari ketiga variabel bebas akan 
meningkat pula pemakaian biaya.

\section{DAFTAR PUSTAKA}

[1] Ahmed, S.M., Azhar S., Kappagntula P. and Gollapudil D. (2003). Delays in construction: a brief study of the Florida construction industry. Proceedings of the 39th Annual ASC Conference, Clemson University, Clemson, SC, pp. 25766.

[2] Ahyari,Agus.1987. Pengendalian system Produksi.Buku 1 dan 2. BPEF: Yogyakarta.

[3] Aibinu and Jagboro ,2002, The_effects_of_construction_delays_on_project delivery_in_Nigerian_construction_id ustry. Alaghbari W.A.M., Razali M.A.K., Salim,

[4] A. and Ernawati (2005). Factors affecting construction speed of industrialized building systems in Malaysia. Universiti Putra Malaysia: Master"s thesis.

[5] Assaf et al. (1995).Causes of delay in large building contruction project.

[6] Austen A.D., danR.H. Neale, 1994, ManajemenProyekKonstruksiPedoman,Proses danProsedur, PPM dan PT Pustaka Binaman Pressindo, Jakarta.

[7] Burhan Bungin, 2014, Metodologi PenelitianKuantitatif. Jakarta:Kencana Prenamedia Group.

[8] Callahan, M.T. 1992 Construction Project Scheduling, MC Graw-Hill New York.

[9] Ervianto, Wulfram I. 2005. Manajemen Proyek Konstruksi.Yogyakarta: Andi Offset.

[10] Ghozali, Imam 2013. Aplikasi Analisis Multivatiate dengan Program SPSS. Semarang: Badan Penerbit Universitas Diponegoro.

[11] Kraiem, Z. K. danDiekman, J. E., 1987, Concurent Delays in Construction Projects, Journal of Construction Engineering and Management, ASCE, vol . 113, no. 4, hal.591 602. Kusjadmika hadi, R. Amperawan. 1999. Studi Keterlambatan Kontraktor Dalam melaksanakan Proyek Konstruksi di Daerah Istimewa Yogyakarta. Yogyakarta: UGM.

[12] Levis and Atherley.(1996). Delay construction. Langford: Cahner Books Internasional. Proboyo, Budiman. 1999. Keterlambatan Waktu Pelaksanaan Proyek Klasifikasi dan Peringkat dari Penyebabpenyebabnya.Program Pascasarjana Studi Manajemen Konstruksi Universitas Kristen Petra Surabaya. Surabaya.

[13] Rai Widhiawati I.A, 2009, Penyebab Utama Dari Keterlambatan Penyelesaian Proyek Konstruksi Yang Berada Di Kotamadya Denpasar.

[14] Soeharto, I., 1995, Manajemen Proyek, dari Konseptual sampai Operasional, Erlangga, Jakarta.

[15] Suyatno, 2010, Analisis Faktor Penyebab Keterlambatan Penyelesaian Proyek Gedung (Aplikasi Model Regresi), Universitas Diponegoro, Semarang.

[16] Limantara, A. D., Candra, A. I., \& Mudjanarko, S. W. (2017). Manajemen Data Lalu Lintas Kendaraan Berbasis Sistem Internet Cerdas Ujicoba Implementasi Di Laboratorium Universitas Kadiri. Prosiding Semnastek. 